\title{
Article \\ Preventive Impact of Long-Term Ingestion of Chestnut Honey on Glucose Disorders and Neurodegeneration in Obese Mice
}

\author{
Simona Terzo ${ }^{1}$, Pasquale Calvi ${ }^{1,2}{ }^{-}$, Domenico Nuzzo ${ }^{1,3}{ }^{(0)}$, Pasquale Picone ${ }^{1,3}$, Giacoma Galizzi ${ }^{3}$, \\ Luca Caruana $^{3}$, Marta Di Carlo ${ }^{3}\left(\mathbb{D}\right.$, Laura Lentini ${ }^{1}\left(\mathbb{D}\right.$, Roberto Puleio ${ }^{4}\left(\mathbb{D}\right.$, Flavia Mulè ${ }^{1}$ and Antonella Amato ${ }^{1, *}$
}

\section{check for}

updates

Citation: Terzo, S.; Calvi, P.; Nuzzo,

D.; Picone, P.; Galizzi, G.; Caruana, L.;

Di Carlo, M.; Lentini, L.; Puleio, R.;

Mulè, F.; et al. Preventive Impact of

Long-Term Ingestion of Chestnut

Honey on Glucose Disorders and

Neurodegeneration in Obese Mice.

Nutrients 2022, 14, 756. https://

doi.org/10.3390/nu14040756

Academic Editors: Sonia de

Pascual-Teresa and Lindsay Brown

Received: 16 December 2021

Accepted: 9 February 2022

Published: 11 February 2022

Publisher's Note: MDPI stays neutral with regard to jurisdictional claims in published maps and institutional affiliations.

Copyright: (C) 2022 by the authors. Licensee MDPI, Basel, Switzerland. This article is an open access article distributed under the terms and conditions of the Creative Commons Attribution (CC BY) license (https:// creativecommons.org/licenses/by/ $4.0 /)$.
1 Dipartimento di Scienze e Tecnologie Biologiche, Chimiche e Farmaceutiche (STEBICEF), Università degli Studi di Palermo, 90128 Palermo, Italy; simona.terzo01@unipa.it (S.T.); pasquale.calvi@unipa.it (P.C.); domenico.nuzzo@cnr.it (D.N.); pasquale.picone@cnr.it (P.P.); laura.lentini@unipa.it (L.L.); flavia.mule@unipa.it (F.M.)

2 Dipartmento di Biomedicina, Neuroscienze e Diagnostica Avanzata (Bi.N.D.), Università degli Studi di Palermo, 90127 Palermo, Italy

3 Istituto per la Ricerca e l'Innovazione Biomedica (IRIB), CNR, via U. La Malfa 153, 90146 Palermo, Italy; giacoma.galizzi@irib.cnr.it (G.G.); luca.caruana@irib.cnr.it (L.C.); marta.dicarlo@irib.cnr.it (M.D.C.)

4 Istituto Zooprofilattico Sperimentale della Sicilia "Adelmo Mirri", 90129 Palermo, Italy; roberto.puleioizs@gmail.com

* Correspondence: antonella.amato@unipa.it; Tel.: +39-091-2389-7506
Abstract: The purpose of the present study was to evaluate the impact of long-term honey ingestion on metabolic disorders and neurodegeneration in mice fed a high-fat diet (HFD). Three groups of mice were fed with a standard diet (STD), HFD or HFD supplemented with honey (HFD-H) for 16 weeks. Biochemical, histological, Western blotting, RT-PCR and Profiler PCR array were performed to assess metabolic parameters, peripheral and central insulin resistance and neurodegeneration. Daily honey intake prevented the HFD-induced glucose dysmetabolism. In fact, it reduced plasma fasting glucose, insulin and leptin concentrations and increased adiponectin levels. It improved glucose tolerance, insulin sensitivity and HOMA index without affecting plasma lipid concentration. HFD mice showed a significantly higher number of apoptotic nuclei in the superficial and deep cerebral cortex, upregulation of Fas-L, Bim and P27 (neuronal pro-apoptotic markers) and downregulation of $\mathrm{Bcl}-2$ and BDNF (anti-apoptotic factors) in comparison with STD- and HFD-H mice, providing evidence for honey neuroprotective effects. PCR-array analysis showed that long-term honey intake increased the expression of genes involved in insulin sensitivity and decreased genes involved in neuroinflammation or lipogenesis, suggesting improvement of central insulin resistance. The expressions of p-AKT and p-GSK3 in HFD-H mice, which were decreased and increased, respectively, in HFD mouse brain, index of central insulin resistance, were similar to STD animals supporting the ability of regular honey intake to protect brain neurons from insulin resistance. In conclusion, the present results provide evidence for the beneficial preventative impact of regular honey ingestion on neuronal damage caused by HFD.

Keywords: honey; obesity; neurodegeneration; insulin resistance; HFD mice

\section{Introduction}

Neurodegenerative diseases represent a relevant health problem. Indeed, the World Health Organization has stated that they will become the worldwide second reason of death by the middle of the 21st century after cancer [1]. They include diverse pathological conditions, among which Alzheimer's and Parkinson's diseases are the most prevalent ones [2]. Neurodegeneration is characterized by loss of specific neurons, leading to progressive dysfunctions of the central nervous system. The etiology of neurodegenerative diseases is multifactorial, and it involves mainly aging as well as genetics and environmental factors [3,4]. Currently, it is well accepted that unhealthy lifestyles and dietary habits increase 
the risk of developing neurodegenerative diseases [5]. Indeed, obesity and type 2 diabetes mellitus accelerate the neurodegenerative process, neuroinflammation and oxidative stress accountable for the progressive cognitive decline [6,7]. Actually, the various components of metabolic syndrome (dyslipidemia, obesity, hyperglycemia, insulin resistance and hypertension) cause wide-ranging effects, some of which affect the central nervous system (CNS), and they may result in neurodegenerative diseases [8]. The excessive long-term ingestion of a high-fat diet (HFD) alters body homeostasis, and it participates in the pathogenesis of neurodegeneration [9-11], which is responsible for impairment of cognitive functions in rodents [11].

No effective protective or therapeutic approaches are currently available against obesity-induced brain injury and irreversible loss of neurons. In recent years, various in vitro studies or experiments on preclinical animal models have demonstrated the use of bioactive phytochemicals, such as resveratrol, curcumin, quercetin or functional food, which is able to limit brain damage through their antioxidant and anti-inflammatory properties [12-16].

Honey has been traditionally considered as a supporting factor in medical treatment since ancient times. The health-promoting characteristics are due to the presence of molecules with recognized antioxidants and anti-inflammatory properties [17]. Although honey is speculated to be a potential agent in preventing and reversing metabolic syndrome by reducing obesity, hyperglycemia, dyslipidemia and hypertension [18-22], the consequences of honey chronic ingestion on glucose homeostasis are still debated, and the impact on brain health conditions remains poorly known. Therefore, the present study was undertaken in order to evaluate the effects of regular honey intake on HFD-induced neurodegeneration in an animal model. In addition, we examined if an improvement in glucose dysmetabolism might be directly involved in the eventual neuroprotective effect.

\section{Materials and Methods}

\subsection{Animals and Diets}

The animal procedures for the care and use of laboratory animals were performed accordingly in conformity with the Italian legislative decree n. 26/2014 and the European Directive 2010/63/UE and were authorized by the Ministry of Health (Rome, Italy; Authorization n. 891/2018-PR).

Four-week-old male C57BL/6J mice, purchased from Harlan Laboratories (San Pietro al Natisone Udine, Italy) were housed (two animals per cage) in a room with a controlled environment of temperature $\left(22-24{ }^{\circ} \mathrm{C}\right)$, and relative humidity $(55 \pm 5 \%)$ with $12 \mathrm{~h} \mathrm{light/dark}$ and with free access to food and water ad libitum.

After acclimatization (1 week), the animals were weighed and divided into separated three groups: (A) STD group (STD, $n=8$ ) fed a standard diet consisting of $70 \%$ of energy as carbohydrate, $20 \%$ protein and $10 \%$ fat (code 4 RF25, Mucedola, Milan, Italy) (Table S1) (Supplementary Data); (B) High-fat diet group (HFD, $n=8$ ), fed HFD (PF4215, Mucedola, Milan, Italy) that, as previously described [23], supplied $60 \%$ of energy as fat, $20 \%$ protein and 20\% (Table S1) (Supplementary Data); and (C) Mice fed an HFD supplemented with Sicilian black bee chestnut honey (HFD-H, $n=8)$. HFD-H was obtained by substituting part of the HFD with honey in order to have the same caloric value of HFD. The honey amount was chosen on the basis of previous reports [24], and it corresponds to $45 \mathrm{mg}$ honey ingested/day/mouse. The honey composition is reported in Table S2 (Supplementary Data). The honey amount was chosen on the basis of previous reports [24], and it corresponds to $45 \mathrm{mg}$ honey ingested/day/mouse. Bodyweight and food intake were detected weekly throughout the study.

At the end of the study period, metabolic parameters were analyzed, then the animals were weighed and sacrificed by cervical dislocation. Blood was immediately drawn by cardiac puncture, and plasma was recovered after centrifugation at $3000 \mathrm{rpm}$ at $4{ }^{\circ} \mathrm{C}$ for $15 \mathrm{~min}$ and stored at $-80^{\circ} \mathrm{C}$ until analysis. The aorta was cannulated and perfused with 
Dulbecco's buffered solution containing 2 mM EDTA and incision of the right atrial allowed blood outflow. Brains were explanted, weighed and processed for subsequent analysis.

\subsection{Metabolic Parameters}

Plasma triglyceride, total cholesterol, HDL and LDL concentrations were measured using the ILAB 600 Analyzer (Instrumentation Laboratory, Bedford, MA, USA). Fasting blood glucose concentrations were determined by a glucometer (GlucoMen LX meter, Menarini, Florence, Italy). Intraperitoneal glucose tolerance test (IPGTT) and insulin tolerance test (ITT) were carried out in overnight fasting mice. For IPGTT, mice were injected intraperitoneally (i.p.) with glucose $(2 \mathrm{~g} / \mathrm{kg} \mathrm{b.w.)}$ (D-glucose, Sigma-Aldrich, Milan, Italy) in $0.9 \%$ saline. For ITT, mice were injected i.p. with insulin $(0.5 \mathrm{U} / \mathrm{kg}$ b.w.) (Insuman Rapid, Sanofi Aventis, Italy) in $0.9 \%$ saline. Glucose concentrations were measured at different time intervals $(0,15,30,60,120 \mathrm{~min})$ by tail vein. Plasma insulin was quantified using a mouse ELISA kit (Alpco diagnostics, Salem, NH, USA) according to the manufacturer's instructions. The HOMA-IR index was calculated as the product of fasting insulin $(\mathrm{ng} / \mathrm{mL})$ and fasting glucose $(\mathrm{mg} / \mathrm{dL})$ divided by the constant 22.5 .

ELISA kits were used to determine plasma leptin (Life Technologies, Frederick, MD, USA) and adiponectin (Crystal Chem, Elk Grove Village, IL, USA).

\subsection{Brain Tissue Preparation}

Brains obtained from all the groups of animals were coronally cut into two halves. One part was frozen in liquid nitrogen and stored until the subsequent analysis. The other half brain was fixed in $4 \%$ formalin for $24 \mathrm{~h}$, dehydrated by graded ethanol $(50 \%, 70 \%, 85 \%$, $96 \%$ for $5 \mathrm{~min}$ ), then embedded in paraffin overnight and subsequently sectioned ( $5 \mu \mathrm{m}$ thick) using a microtome for histological analysis.

\subsection{TUNEL Assay}

Terminal deoxynucleotidyl Transferase Biotin-dUTP Nick End Labeling (TUNEL) assay was used to detect apoptotic nuclei in brain sections by using a cell death detection kit (Promefa, Madison, WI, USA) according to the manufacturer's instructions. The number of apoptotic cells was counted in the cerebral cortex selected fields by two of us blind to ingested diet, and the ratio of apoptotic cells per brain area was calculated.

\subsection{Western Blotting and PCR}

Total proteins were prepared by resuspending $10 \mathrm{mg}$ of frozen homogenate in lysis buffer (50 mM Tris- $\mathrm{HCl}$, pH 7.4; $150 \mathrm{mM} \mathrm{NaCl}, 0.5 \%$ Triton X-100, $2 \mathrm{mM}$ phenylmethylsulfonyl fluoride, $1 \mathrm{mM}$ DTT, $0.1 \% \mathrm{SDS}$ ) with protease inhibitors (Amersham, Life Science, Les Ulis, France) and phosphatase inhibitor cocktail II (Sigma-Aldrich, Milan, Italy). Then, they were quantified by the Bradford method (Bio-Rad, Segrate, Italy). Protein (50 $\mu \mathrm{g}$ ) were resolved by $12 \%$ acrylamide gel and transferred onto nitrocellulose filters for Western blotting using anti-GSK-3 $\alpha / \beta$ (D75D3) \#5676 (1:1000), anti-phosphoGSK-3 $\beta$ (Tyr216) \#44-604G (1:500), anti-AKT \#9272 (1:1000), anti-phospho-AKT (S473) (D9E) \#4060 (1:500), anti-insulin receptor (E9L5V) \#23413 (1:500), anti-Erk (137F5) \#4695 (1:1000), anti-phosphoErk (Thr202/Tyr204) \#4370 (1:1000), anti- $\beta$-Actin A5441 (1: 10,000). All antibodies were supplied by Cell Signaling Technology (Danvers, MA, USA) except anti-phosphoGSK$3 \beta$ (Tyr216) supplied by Thermofisher and anti- $\beta$-actin by Sigma-Aldrich (St. Louis, MI, USA). The primary antibodies were revealed by using secondary antibodies (anti-mouse or anti-rabbit) labeled with infrared fluorescent dye IR680 (1:10,000; LI-COR). Secondary antibodies were detected by LI-COR ${ }^{\circledR} 150$ Platform (LI-COR, Lincoln, NE, USA), according to the manufacturer's instructions. Band intensities were analyzed with the Odyssey ${ }^{\circledR}$ CLx Imaging System (Li-Cor, Lincoln, NE, USA), and expression was adjusted to the $\beta$-actin expression. The protein levels were expressed as intensity relative to the control.

For RT-PCR, RNA was extracted using the RNeasy Plus Mini Kit (Qiagen, Valencia, CA, USA). Two ng of RNA were used to obtain cDNA using High Capacity cDNA Reverse 
Transcription (Applied Biosystems, Bedford, MA, USA). Gene expression was performed using primers listed in Table 1.

Table 1. Oligonucleotide sequence of primers for RT-PCR.

\begin{tabular}{|c|c|c|c|}
\hline Gene & Forward Primer & Reverse Primer & $\mathrm{T}^{\circ}$ Annealing \\
\hline Fas- $L$ & 5'-CAAGTCCAACTCAAGGTCCATGCC-3' & 5'-AGAGAGAGCTCAGATACGTTTGAC-3' & $58^{\circ} \mathrm{C}$ \\
\hline Bim & 5'-AACCTTCTGATGTAAGTTCT-3' & 5'-GTGATTGCCTTCAGGATTAC-3' & $58{ }^{\circ} \mathrm{C}$ \\
\hline$p 27$ & $5^{\prime}$-TGCGAGTGTCTAACGGGAG-3' & 5'-GTTTGACGTCTTCTGAGGCC-3' & $59^{\circ} \mathrm{C}$ \\
\hline Bcl-2 & 5'-ATGTGTGTGGAGAGCGTCAA-3' & $5^{\prime}$-AGAGACAGCCAGGAGAAATCA-3' & $47^{\circ} \mathrm{C}$ \\
\hline$B D N F$ & 5'-GGCTGACACTTTTGAGCACGTC-3' & 5'-CTCCAAAGGCACTTGACTGCTG-3' & $52{ }^{\circ} \mathrm{C}$ \\
\hline$I L-1 \beta$ & 5'-TCATGGGATGATGATAACCTGCT-3' & 5'-CCCATACTTTAGGAAGACACGATT-3' & $50{ }^{\circ} \mathrm{C}$ \\
\hline$I L-6$ & 5'-CTGGTGACAACCACGGCCTTCCCT-3' & 5'-ATGCTTAGGCATAACGCACTAGGT-3' & $54{ }^{\circ} \mathrm{C}$ \\
\hline$T N F-\alpha$ & 5'-AGCCCACGTCGTAGCAAACCA-3' & 5'-GCAGGGGCTCTTGACGGCAG-3' & $53^{\circ} \mathrm{C}$ \\
\hline B-actin & 5'-CGGGATCCCCGCCCTAGGCACCAGGGT-3' & 5'-GGAATTCGGCTGGGGTGTTGAAGGTCTCAAA-3' & $60{ }^{\circ} \mathrm{C}$ \\
\hline
\end{tabular}

The amplification cycles included denaturation at $95^{\circ} \mathrm{C}$ for $45 \mathrm{~s}$, annealing for $45 \mathrm{~s}$, and elongation at $72{ }^{\circ} \mathrm{C}$ for $45 \mathrm{~s}$. After 35 cycles, the amplification products were separated by electrophoresis, and the gels were stained with $1 \mathrm{mg} / \mathrm{mL}$ ethidium bromide and visualized with ultraviolet (UV) light using E-Gel GelCapture (Thermo Fisher Scientific, Monza, Italy). The expression levels of the gene targets, normalized to the endogenous reference ( $\beta$-actin), were analyzed using E-Gel GelQuant Express Analysis Software (Thermo Fisher Scientific, Monza, Italy).

\subsection{RT2Profiler PCR Array}

Mouse insulin resistance arrays (Insulin Resistance PCR Array, QIAGEN, Monza, Italy) in 96-well plate format were used to assay gene expression changes in the brain. Samples were prepared from pooled RNA extracted from STD, HFD and HFD-H mouse brains. Samples were added to the reaction plates following the manufacturer's instructions, and a StepOne Real-Time instrument (Applied Biosystem) was used to perform the array. Analysis was performed using the relative quantification method $\left(2^{-\Delta \Delta \mathrm{CT}}\right)$.

\subsection{Statistical Analysis}

The results are presented as mean \pm S.E.M. Statistical evaluation was performed by ANOVA, followed by Bonferroni post hoc test using Prism 6.0, GraphPad (San Diego, CA, USA). Results with a $p$-value $<0.05$ were considered statistically significant.

\section{Results}

\subsection{Honey Ingestion and Metabolic Parameters}

All animals gained weight during the experimental period. The bodyweight of HFD and HFD-H mice was significantly higher than STD mice, but no difference was observed when compared HFD-H to HFD. Although the daily caloric intake of HFD-mice was higher than STD mice, it did not result in significantly different in comparison with HFD-H mice (Figure 1A,B). HFD chronic ingestion-induced dyslipidemia, i.e., plasma triglyceride, total cholesterol, low-density lipoprotein (LDL), were increased while levels of high-density lipoproteins (HDL) were reduced in comparison with STD mice (Figure 1C). Honey supplementation failed to prevent the lipid concentration changes associated with HFD consumption (Figure 1C). 
A

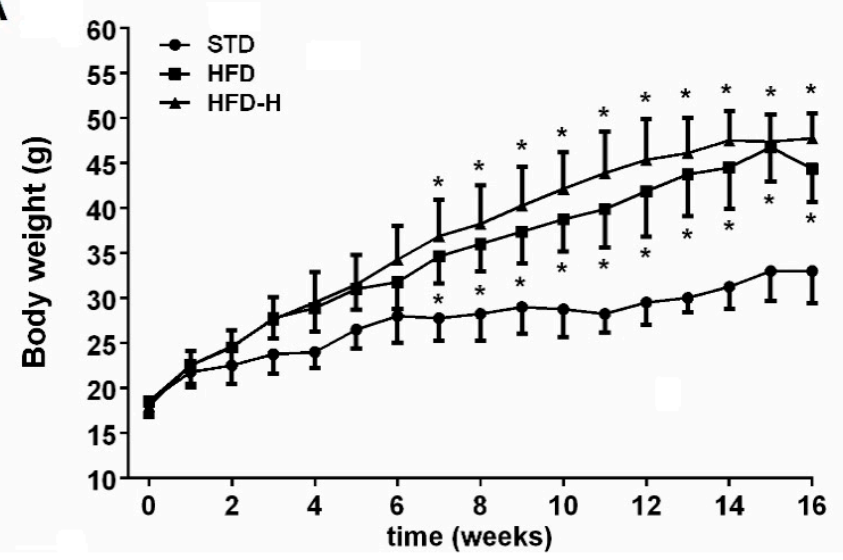

B

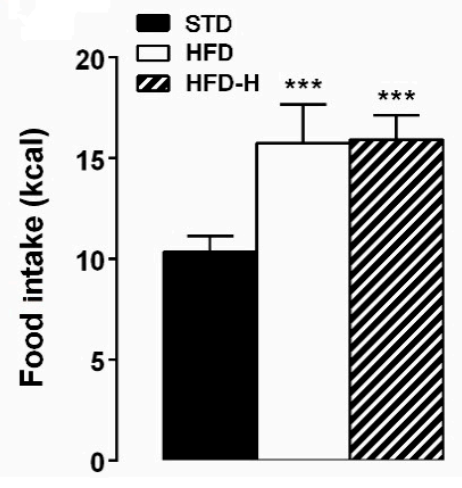

C

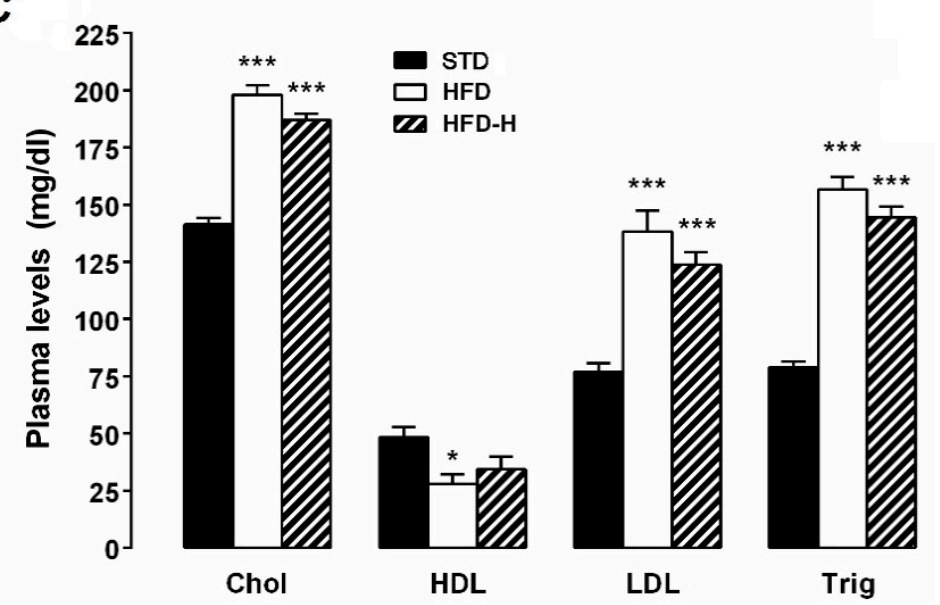

Figure 1. Effects of long-term honey ingestion on metabolic parameters in HFD mice. Honey failed to prevent weight gain and dyslipidemia in HFD mice. (A) Bodyweight; (B) Daily food intake; (C) Plasma concentrations of triglycerides, cholesterol, HDL and LDL in the different groups of mice. Data are mean values \pm S.E.M. $\left(n=8\right.$ /group). ${ }^{*} p<0.05,{ }^{* * *} p<0.001$ vs. STD mice.

\subsection{Honey Ingestion Improves Glucose Metabolism in HFD Mice}

After 16 weeks on HFD, mice presented hyperglycemia with fasting glucose concentrations $296.6 \mathrm{mg} \pm 14.8 \mathrm{mg} / \mathrm{dL}(n=8)$ significantly higher than STD mice $(146.8 \pm 9.9 \mathrm{mg} / \mathrm{dl}$, $n=8$ ). Honey supplementation improved fasting glucose concentrations. Indeed, glycemia value in HFD-H mice was significantly lower than HFD and similar to STD, suggesting a preventive action against hyperglycemia (Figure 2A). In HFD mice, fasting plasma insulin concentration was three-fold higher compared to STD mice. In HFD-H mice, the 
increase in plasma insulin caused by HFD was mitigated (Figure 2B). In addition, HFD mice displayed an impaired glycemic response following an intraperitoneal glucose load. Glucose tolerance test demonstrated that basal glycemia increased to a maximum after 15 min of glucose intraperitoneal injection in HFD and STD groups, but this maximum was significantly higher and maintained more elevated in HFD mice than in STD mice (Figure 2C). HFD-H mice showed improved glycemic control as indicated by the reduction in blood glucose levels during the i.p. glucose tolerance test (Figure 2C). The HFD group showed the Glucose area under the curve (AUC) significantly increased compared to STD or HFD-H groups (Figure 2D). The glucose clearance rate in response to exogenous insulin was evaluated in the different animal groups by insulin tolerance test. The rate of glucose clearance in response to exogenous insulin $(0.5 \mathrm{U} / \mathrm{kg})$ was reduced in HFD mice in comparison with STD mice. Honey supplementation prevented the loss of insulin sensitivity induced by HFD, as showed by the area under the curve for the insulin tolerance test (Figure 2E,F). Accordingly, HOMA-IR, an index of insulin resistance, was significantly higher in HFD mice than STD- or HFD-H animal groups (Figure 2G). Overall, our results suggest that honey supplementation is able to prevent/mitigate the peripheral insulin resistance induced by HFD consumption.

A

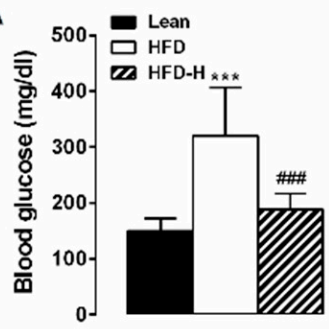

C

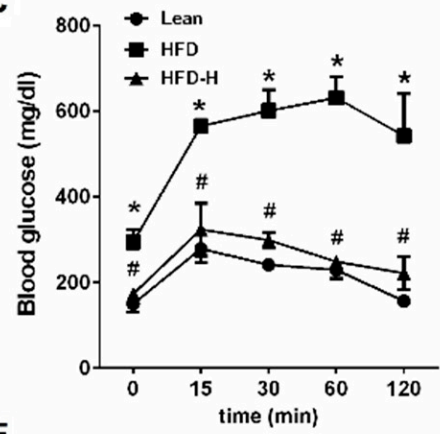

E

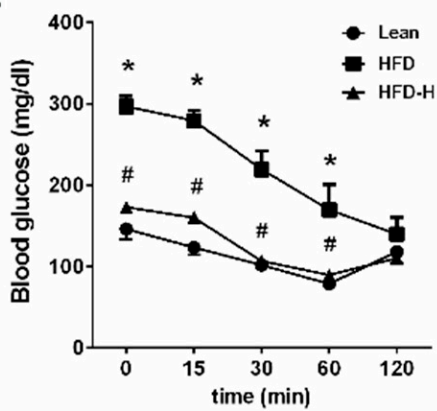

B

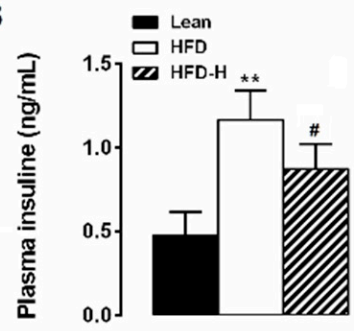

D

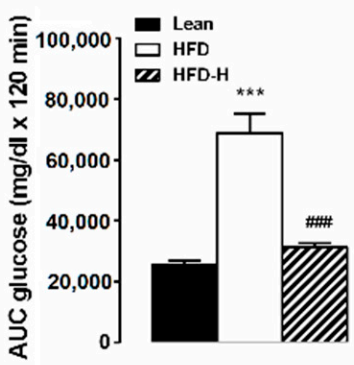

F

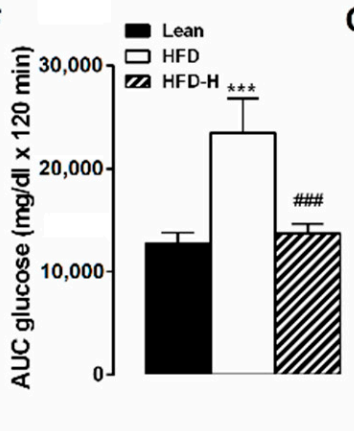

G

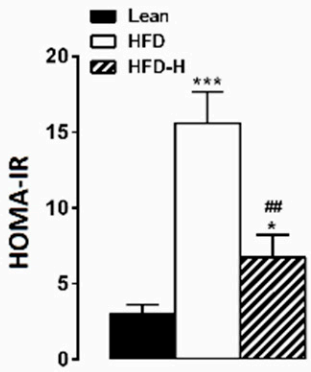

Figure 2. Effects of long-term honey ingestion on glucose metabolism in HFD mice. Honey prevented the glucose dysmetabolism. (A) Fasting glucose concentration; (B) Fasting insulin concentration; (C) Plasma glucose concentration during intraperitoneal glucose tolerance test (IPGTT). (D) Area under the curve (AUC) during IPGTT; (E) Glucose concentrations during insulin tolerance test (ITT). (F) AUC for blood glucose concentrations during ITT; (G) HOMA-index calculated as fasting glucose $(\mathrm{mg} / \mathrm{dL}) \times$ fasting insulin $(\mathrm{ng} / \mathrm{mL}) / 22.5$. Data are mean values \pm S.E.M. $(n=8$ mice/group $)$. ${ }^{*} p<0.05,{ }^{* *} p<0.01,{ }^{* * *} p<0.001$ vs. STD mice; ${ }^{\#} p<0.05$, ${ }^{\# \#} p<0.01$, \#\#\# $p<0.001$ vs. HFD-fed mice. 


\subsection{Honey Ingestion Mitigates Neurodegeneration Induced by HFD}

Whole-brain weight was determined at the sacrifice moment, and the brain/body weight ratio was calculated. The HFD brain mean weight was significantly lower than STD or HFD-H (Figure 3A) as well as the mean brain/body weight (Figure 3B). Moreover, we used the TUNEL assay in order to examine the number of apoptotic cells in superficial and deep cortical sections. We found a higher number of TUNEL-positive neurons in HFD mice than in STD- or HFD-H mice, suggesting a decrease in apoptotic cell death in the brain of HFD-H mice (Figure 3C-F).

A

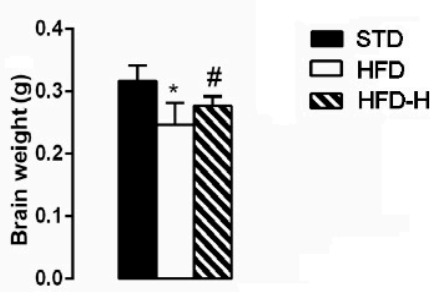

C

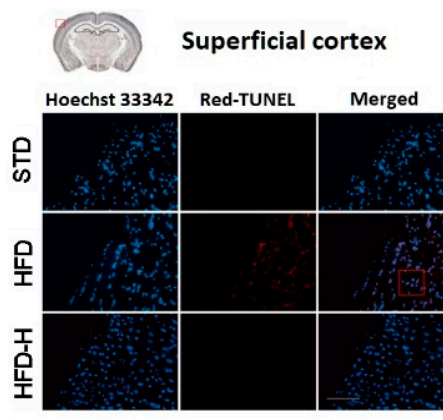

$\mathbf{E}$

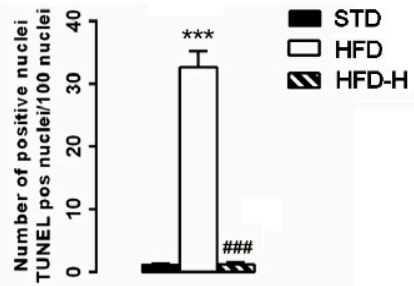

B

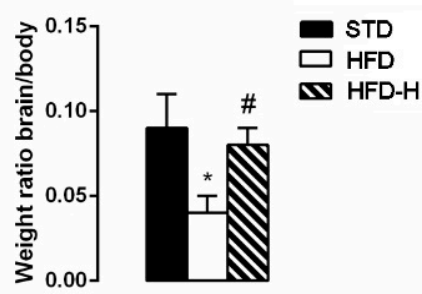

D

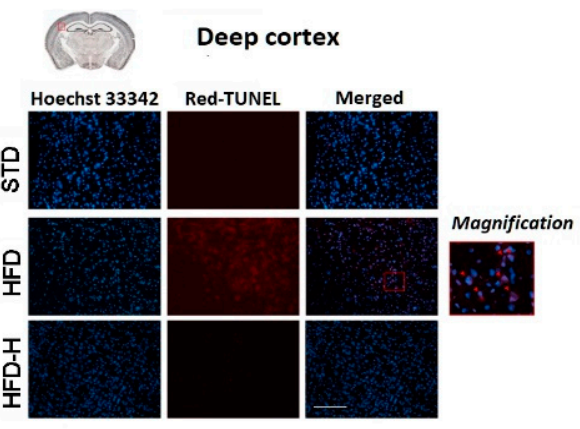

$\mathbf{F}$

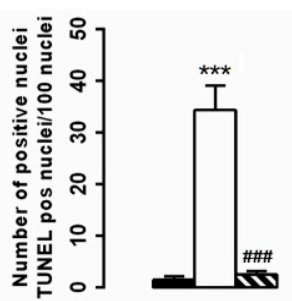

$\square$ STD

$\square$ HFD

W HFD-H

Figure 3. Impact of long-term honey ingestion on neuronal damage caused by HFD. Honey prevented neurodegeneration in HFD mice. (A) Brain weight; (B) Weight ratio brain/body; (C) TUNEL assay on superficial cerebral cortex sections; (D) TUNEL assay on deep cerebral cortex sections; (E) Number of apoptotic nuclei in superficial and deep (F) cerebral cortex in STD, HFD and HFD-H mice. Data are mean values \pm S.E.M. $\left(n=8\right.$ /group). ${ }^{*} p<0.05,{ }^{* * *} p<0.001$ vs. STD; ${ }^{*} p<0.05,{ }^{\# \#} p<0.001$ vs. HFD-fed mice. Microscope magnification $10 \times$. Scale bar, $200 \mu \mathrm{m}$.

Honey supplementation was also able to prevent the increase in pro-apoptotic gene expressions, such as Fas-L and p-27, and the decrease in anti-apoptotic genes, such as Bcl-2 and BDNF caused by HFD, suggesting a neuroprotective effect of chronic honey ingestion (Figure 4A,B). 
A
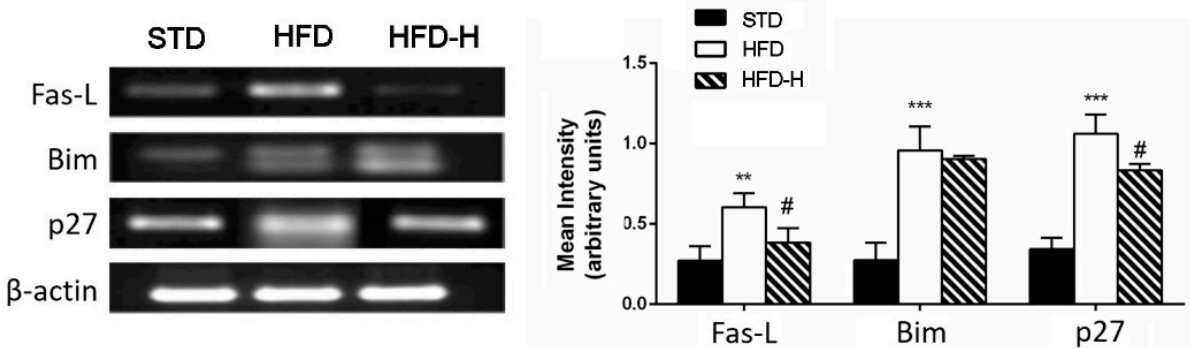

B
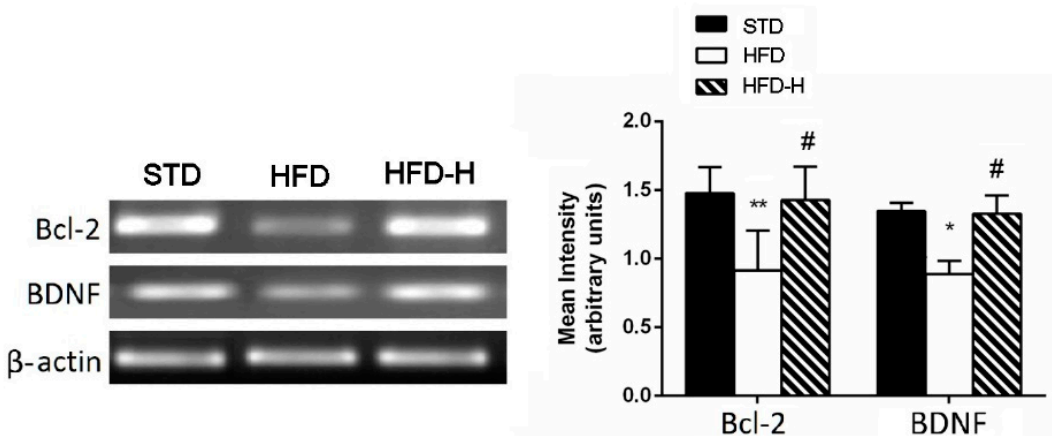

Figure 4. Effects of long-term honey ingestion on apoptosis-related gene expression in HFD mice. Honey downregulated pro-apoptotic gene expression and upregulated anti-apoptotic genes. (A) Representative images of the RT-PCR results and mRNA levels of pro-apoptotic genes: Fas-L, Bim and p27; (B) RT-PCR results and mRNA levels of survival genes: Bcl-2 and BDNF. Data are mean values \pm S.E.M. ( $n=8$ /group). ${ }^{*} p<0.05,{ }^{* *} p<0.01,{ }^{* * *} p<0.001$ vs. STD mice; ${ }^{*} p<0.05$ vs. HFD. STD: standard mice; HFD: high fat diet mice; HFD-H: high fat diet supplemented with honey mice.

\subsection{Honey Ingestion Improves Insulin Signaling in Brains of HFD Mice}

In order to verify if honey ingestion also improves central insulin resistance, we investigated the effects of HFD and honey supplementation on insulin signaling in the brain. Insulin receptor, AKT and GSK3- $\beta$ expression were detected by Western blotting. In the brain, HFD feeding for 16 weeks decreased the expression of IR, p-Akt/Akt and upregulated GSK3- $\beta$ / p-GSK3- $\beta$ compared to controls. Honey supplementation prevented the down/upregulation of these alterations associated with HFD consumption (Figure 5), suggesting that chronic honey ingestion improves the impairment of insulin signaling in obesity conditions.
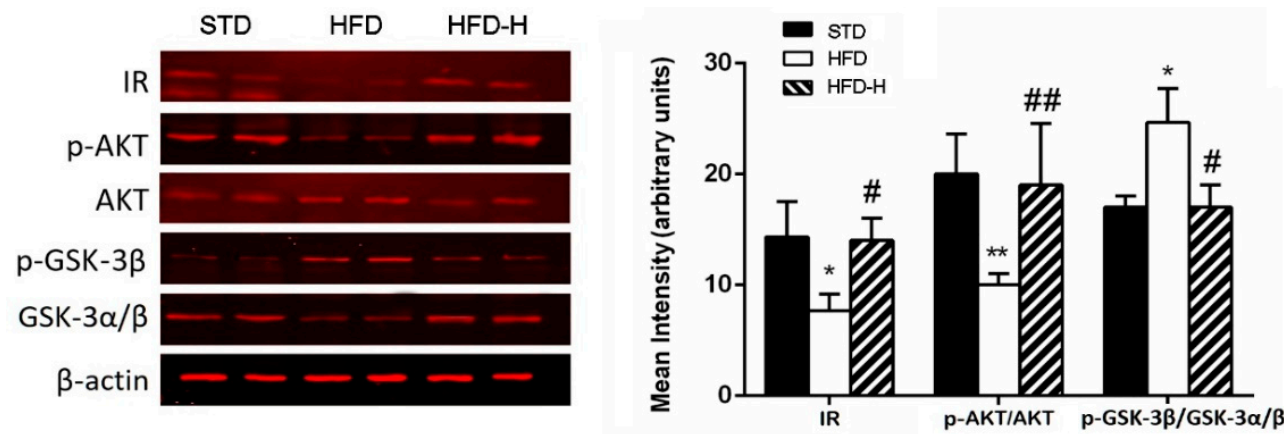

Figure 5. Effects of long-term honey ingestion on expression of insulin signaling protein HFD mice. Honey improved insulin signaling in HFD brain. Western blot of protein extracted from brain lysates of different mouse groups and incubated with anti-insulin receptor (IR), anti-p-AKT, anti-AKT, anti-pGSK- $3 \beta$, anti-GSK- $3 \alpha / \beta$ and $\beta$-actin antibodies. Honey prevented the expression changes in insulin receptor (IR), p-AKT and p-GSK-3 caused by HFD. Data are mean values \pm S.E.M. ( $n=8 /$ group). ${ }^{*} p<0.05,{ }^{* *} p<0.01$ vs. STD mice; ${ }^{\#} p<0.05$, \#\# $p<0.01$ vs. HFD. STD: standard mice; HFD: high fat diet mice; HFD-H: high fat diet supplemented with honey mice. 
In addition, we assessed expression changes in genes involved in central insulin resistance by using a Profiler PCR array. Twelve genes were up or downregulated by more than Two-fold in HFD-H fed mice compared to HFD. More specifically, we found an upregulation of adipokine Receptor (adipoR1 and adipoR2), insulin receptor (InsR) and its substrate (Irs1), and a downregulation of proinflammatory genes such as Rbp4, Cd36 e Stat3 (Table 2).

Table 2. Expression profiles of genes in HFD-H/HFD which were significantly upregulated or downregulated by 2 -folds.

\begin{tabular}{clc}
\hline Gene Name & \multicolumn{1}{c}{ Protein } & HFD-H/HFD \\
\hline Acs14 & Acyl-CoA synthetase long-chain family member 4 & -2.30 \\
Adgre1 & Adhesion G Protein-Coupled Receptor E1 & -2.12 \\
Adipor1 & Adiponectin receptor 1 & 2.47 \\
Adipor2 & Adiponectin receptor 2 & 2.32 \\
Cd36 & CD36 antigen & -3.33 \\
Cebpa & CCAAT/enhancer binding protein (C/EBP), alpha & -2.83 \\
Insr & Insulin receptor & 3.77 \\
Irs1 & Insulin receptor substrate 1 & 4.17 \\
Lepr & Leptin receptor & 5.44 \\
Rbp4 & Retinol binding protein 4, plasma & -4.46 \\
Srebf2 & Sterol regulatory element binding factor 2 & -2.12 \\
Stat3 & Signal transducer and activator of transcription 3 & -2.39 \\
\hline
\end{tabular}

\subsection{Honey Supplementation Modifies Blood Levels of Leptin and Adiponectin}

Compared with the levels in the STD group, the HFD mice displayed significantly higher leptin and lower adiponectin plasma concentrations (Figure 6). Honey supplementation prevented the changes in the plasma levels of these hormones (Figure 6).
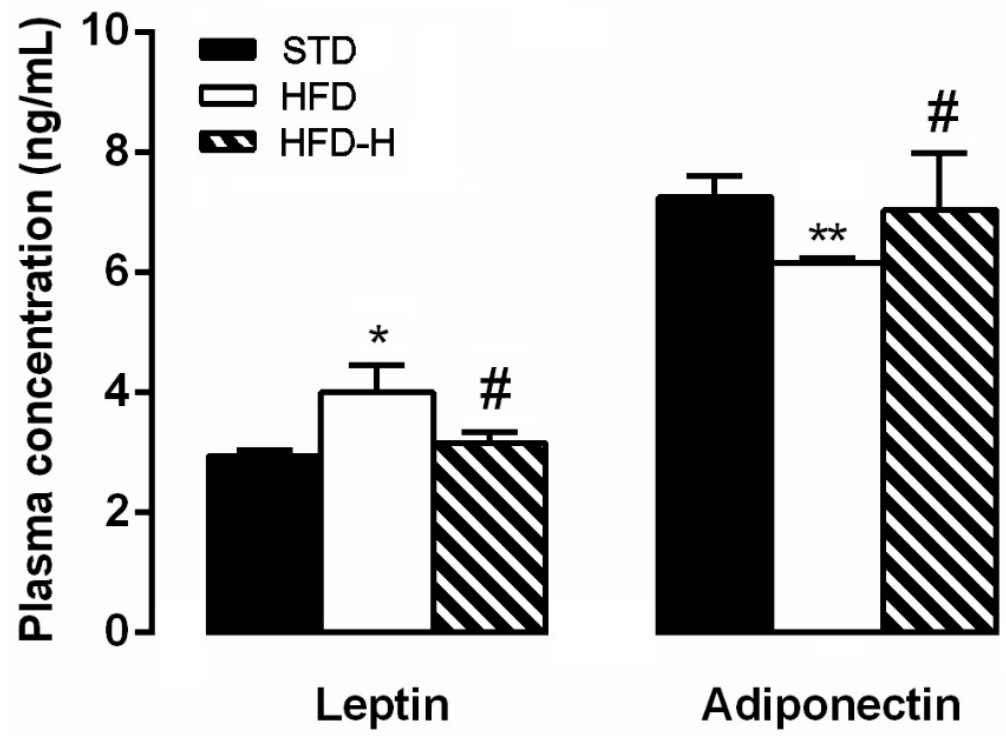

Figure 6. Effects of long-term honey ingestion on leptin and adiponectin concentration in HFD mice. Honey prevented the changes in plasma levels caused by HFD. Data are mean values \pm S.E.M. ( $n=8$ /group). ${ }^{*} p<0.05,{ }^{* *} p<0.01$ vs. STD mice; ${ }^{\#} p<0.05$ vs. HFD. STD: standard mice; HFD: high fat diet mice; HFD-H: high fat diet supplemented with honey mice.

\section{Discussion}

The major findings from the present study suggest that honey ingestion effectively attenuates obesity-related peripheral and central insulin resistance. Moreover, honey ingestion prevents HFD-induced neurodegeneration by modulating positively brain gene ex- 
pression involved in insulin signaling, neuroinflammation, apoptosis and some adipokine receptors.

Nowadays, it is widely documented that obesity, type 2 diabetes or different metabolic disorders, including metabolic syndrome and NAFLD, increase the risk of cognitive decline, and these diseases have been linked to AD-type pathology [25-29]. In our study, we induced obesity in mice by HFD because this approach mimics the usual route of obesity occurrence in humans, causing positive energy balance and an increase in visceral fat [30]. In addition, in rodents, long-term HFD intake results in obese peripheral and central insulin resistance and impaired brain functions, as suggested by the presence of brain mitochondrial dysfunction oxidative stress, neuroinflammation, impaired synaptic plasticity and cognitive decline $[10,15,31-36]$. Therefore, an HFD obese mouse is a useful model for verifying the impact of functional food on obesity-related impairments, including neurodegeneration.

The results of the present study provide evidence for the beneficial effects of chronic honey ingestion in obese mice. In particular, dietary honey supplementation prevented the fasting hyperglycemia and the impairment of the glucose response during the glucose tolerance test, and it improved the plasma insulin concentration, insulin sensitivity and HOMA index, suggesting a preventive effect of the long-term honey ingestion in HFDinduced impairment of glucose homeostasis. On the other hand, honey hypoglycemic properties have been pointed out not only in diabetes rodent models but also in healthy subjects and diabetic patients $[17,22,37,38]$. In our experimental conditions, we did not observe any significant impact on weight gain or plasma lipid concentrations in HFD-H mice, ruling out an improvement of lipid metabolism as responsible for the observed effects on glucose metabolism.

Moreover, our results obtained from Western blotting and microarray experiments suggest that alterations in glucose homeostasis induced by HFD consumption in mice are associated with impaired insulin signaling in the brain, and this effect is mitigated by honey supplementation. In fact, the expressions of p-AKT and p-GSK3 in HFD-H mice, which, respectively, decreased and increased in HFD mouse brain, index of central insulin resistance, were similar to STD animals. Moreover, the downregulation of insulin receptor and its substrate, Irs1, found in the brain of HFD mice, was not observed in HFD-H mice, supporting the hypothesis that regular intake of honey restored brain insulin signaling in HFD obese mice. To our knowledge, this is the first study to provide evidence for honey's ability to improve brain insulin signaling. The capacity of regular honey consumption to improve brain insulin signaling could explain its protective role on neuronal function. In fact, insulin resistance has been reported to lead to impairment of neuronal homeostatic functions, oxidative stress, DNA damage, mitochondrial dysfunction, and, consequently, cell death [28,39]. Moreover, it is well accepted that impairment of insulin signaling leads to the downregulation of various neuroprotective genes [29]. Therefore, chronic ingestion of honey could protect the brain from HFD-caused damage by improving central insulin sensitivity. In fact, in our experimental model, HFD induced chronic neurodegeneration as suggested by the lower brain/body weight ratio and the higher number of apoptotic neurons in the HFD cortex than STD. However, honey supplementation attenuated these detrimental effects suggesting a neuroprotective effect of chronic honey ingestion. Moreover, previous studies on animals reported that intake of honey was beneficial and improved memory loss and cognitive decline caused by different conditions, such as aging, stress, ovariectomy [40-42] and neuroinflammation induced by A $\beta-42$ injection [43]. The beneficial effects of honey on the brain have been associated with the presence of components such as flavonoids and phenolic acids that can improve oxidative stress and oxidative stress-linked effects $[17,44,45]$.

Although we did not take into account the oxidative state of the HFD-brain, our results clearly show that honey exerts neuroprotective effects on the HFD brain because it was able also to prevent the increase in pro-apoptotic gene expressions, such as Fas-L and p-27, and the HFD-caused decrease in anti-apoptotic genes and survival factors, such as Bcl-2 
and BDNF. Moreover, the downregulation of inflammation-related genes, such as Cd36, Adgre1 or Acsl4 that promotes proinflammatory cytokine production from microglia and neuronal death [46], as revealed by our microarray experiments, supports, once more, the honey neuroprotective properties. A positive effect due to the honey ingestion could be represented by a reduction in retinol-binding protein 4 (RBP4) gene expression. In fact, RBP4 is an adipokine related to the dysregulation of energy metabolism, insulin resistance, diabetes mellitus and obesity [47], and it was reported to play a role also as an inflammatory neurotrophic adipokine [48]. In addition, suppression of signal transducer and activator of transcription 3 (STAT3) in the HFD-H brain would represent evidence for a positive impact of honey because STAT3 was related to different microglia-dependent proinflammatory responses [49-51].

Disturbed neuronal lipid and cholesterol homeostasis has been linked to central insulin resistance contributing to the pathogenesis of neurodegenerative diseases, such as Alzheimer's disease (AD) $[15,52,53]$. In the current study, genes related to lipogeneses, such as CCAAT/enhancer-binding protein (Cebpa) and sterol regulatory element-binding factor 2 (Srebf2), were downregulated in the HFD-H brain in comparison with the HFD brain, suggesting a further mechanism by which honey supplementation can protect the cerebral neurons.

Since dysregulated leptin and adiponectin secretions were reported to be one of the links among obesity, insulin resistance and neurodegenerative disorders [54], we measured plasma levels of these adipokines in the different animal groups. On the other hand, receptors for these adipokines, present in various brain regions, are involved in the pathogenesis of neurodegenerative diseases $[54,55]$. It is well accepted that in obesity, leptin resistance develops, leading to increased leptin production by adipose tissue and hyperleptinemia in an attempt to compensate for the low leptin responsiveness [56]. Therefore, leptin plasma levels are related positively to adiposity [57]. Leptin levels were lower in the HFD-H group than HFD mice, despite the fact that the fat mass was similar, suggesting the ability of honey to prevent also the leptin unbalance caused by HFD. Moreover, central leptin resistance mediated by downregulation of leptin receptors (Lepr) and/or by deficient leptin signaling downstream LepRs are involved in neuronal deficits [58]. Therefore, the brain upregulation of Lepr gene induced by honey ingestion could be considered as one of the mechanisms involved in honey neuroprotection. In our study, the plasma level changes in adiponectin caused by honey can be interpreted as an improvement tool of insulin resistance and the consequent neuronal impairment. In fact, adiponectin is reported to increase insulin sensitivity to have anti-inflammatory and antioxidant activity [58]. Indeed, reduced levels of circulating adiponectin are found in obesity, likely causing insulin resistance [59]. Moreover, adiponectin and adiponectin receptor (AdipoRs) agonists are known to be neuroprotective in primary rat hippocampal neurons and various rodent models of cerebral damage $[58,60,61]$, and we found a higher expression of adipoRs in the brain of HFD-H mice in comparison with HFD mice.

\section{Conclusions}

The present study suggests that long-term ingestion of chestnut honey attenuates peripheral and central insulin resistance and prevents HFD-induced neurodegeneration by modulating positively brain gene expression involved in insulin signaling, neuroinflammation, apoptosis and some adipokine receptors. Our results support the functional action of chronic honey consumption that could be achieved considering a daily honey intake of about $10 \mathrm{~g}$ [62]. 


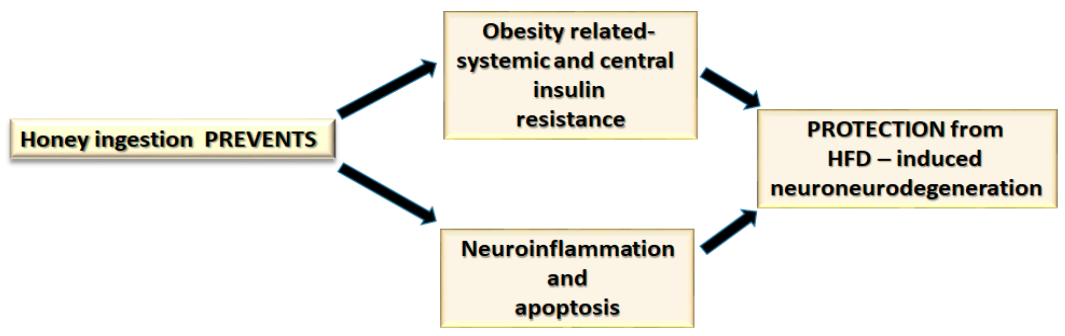

Supplementary Materials: The following supporting information can be downloaded at: https: //www.mdpi.com/article/10.3390/nu14040756/s1. Table S1: Composition of the different diets. Table S2: Composition of honey.

Author Contributions: Acquisition, analysis and interpretation of data, S.T.; contribution to data acquisition and analyses, P.C.; investigation and data curation, D.N.; biomolecular and histological analysis, P.P.; investigation, G.G. and L.C.; conceptualization, M.D.C.; acquisition data, L.L.; contribution to data acquisition, R.P.; supervision and manuscript editing, F.M.; conception and design of the study, writing-original draft, A.A. All authors have read and agreed to the published version of the manuscript.

Funding: This research did not receive any specific grant from funding agencies in the public, commercial, or not-for-profit sectors.

Institutional Review Board Statement: The study was conducted according to the Italian legislative decree n. 26/2014 and the European Directive 2010/63/UE and approved by the Ministry of Health (Rome, Italy; Authorization n. 891/2018-PR).

Conflicts of Interest: The authors declare no conflict of interest.

\section{References}

1. Menken, M.; Munsat, T.L.; Toole, J.F. The global burden of disease study: Implications for neurology. Arch. Neurol. 2000, 57, 418-420. [CrossRef] [PubMed]

2. Amato, A.; Mulè, F. Protective potential of glucagon like peptide 2 (GLP-2) against the neurodegeneration. Neural Regen. Res. 2019, 14, 1901-1902. [PubMed]

3. Iriti, M.; Vitalini, S.; Fico, G.; Faoro, F. Neuroprotective Herbs and Foods from Different Traditional Medicines and Diets. Molecules 2010, 15, 3517-3555. [CrossRef] [PubMed]

4. Reitz, C.; Brayne, C.; Mayeux, R. Epidemiology of Alzheimer disease. Nat. Rev. Neurol. 2011, 7, 137. [CrossRef] [PubMed]

5. Pugazhenth, S.; Qin, L.; Reddy, P.H. Common neurodegenerative pathways in obesity, diabetes, and Alzheimer's disease. Biochim. Biophys. Acta Mol. Basis Dis. 2017, 1863, 1037-1045. [CrossRef] [PubMed]

6. Kroner, Z. The relationship between Alzheimer's disease and diabetes: Type 3 diabetes? Altern. Med. Rev. 2009, 14, 373-379.

7. Singh-Manoux, A.; Dugravot, A.; Shipley, M.; Brunner, E.J.; Elbaz, A.; Sabia, S.; Kivimaki, M. Obesity trajectories and risk of dementia: 28 years of follow-up in the Whitehall II Study. Alzheimer's Dement. 2018, 14, 178-186. [CrossRef]

8. Van Dyken, P.; Lacoste, B. Impact of Metabolic Syndrome on Neuroinflammation and the Blood-Brain Barrier. Front. Neurosci. 2018, 12, 930. [CrossRef]

9. Keshk, W.A.; Ibrahim, M.A.; Shalaby, S.M.; Zalat, Z.A.; Elseady, W.S. Redox status, inflammation, necroptosis and inflammasome as indispensable contributors to high fat diet (HFD)-induced neurodegeneration; Effect of N-acetylcysteine (NAC). Arch. Biochem. Biophys. 2020, 680, 108227. [CrossRef]

10. Nuzzo, D.; Picone, P.; Baldassano, S.; Caruana, L.; Messina, E.; Gammazza, A.; Cappello, F.; Mulè, F.; Carlo, M. Insulin resistance as common molecular denominator linking obesity to Alzheimer's disease. Curr. Alzheimer Res. 2015, 12, 723-735. [CrossRef]

11. Stranahan, A.M.; Norman, E.D.; Lee, K.; Cutler, R.G.; Telljohann, R.S.; Egan, J.M.; Mattson, M.P. Diet-induced insulin resistance impairs hippocampal synaptic plasticity and cognition in middle-aged rats. Hippocampus 2008, 18, 1085-1088. [CrossRef] [PubMed]

12. Stacchiotti, A.; Corsetti, G. Natural Compounds and Autophagy: Allies against Neurodegeneration. Front. Cell Dev. Biol. 2020, 8 , 555409. [CrossRef] [PubMed]

13. Wilson, D.W.; Nash, P.; Buttar, H.S.; Griffiths, K.; Singh, R.; De Meester, F.; Horiuchi, R.; Takahashi, T. The Role of Food Antioxidants, Benefits of Functional Foods, and Influence of Feeding Habits on the Health of the Older Person: An Overview. Antioxidants 2017, 6, 81. [CrossRef] [PubMed] 
14. Hasnieza Mohd Rosli, N.; Mastura Yahya, H.; Shahar, S.; Wahida Ibrahim, F.; Fadilah Rajab, N. Alzheimer's Disease and Functional Foods: An Insight on Neuroprotective Effect of its Combination. Pak. J. Biol. Sci. 2020, 23, 575-589. [CrossRef] [PubMed]

15. Nuzzo, D.; Galizzi, G.; Amato, A.; Terzo, S.; Picone, P.; Cristaldi, L.; Mule, F.; Di Carlo, M. Regular Intake of Pistachio Mitigates the Deleterious Effects of a High Fat-Diet in the Brain of Obese Mice. Antioxidants 2020, 9, 317. [CrossRef]

16. Nuzzo, D.; Amato, A.; Picone, P.; Terzo, S.; Galizzi, G.; Bonina, F.P.; Mulè, F.; Di Carlo, M. A Natural Dietary Supplement with a Combination of Nutrients Prevents Neurodegeneration Induced by a High Fat Diet in Mice. Nutrients 2018, 10, 1130. [CrossRef]

17. Terzo, S.; Mulè, F.; Amato, A. Honey and obesity-related dysfunctions: A summary on health benefits. J. Nutr. Biochem. 2020, 82, 108401. [CrossRef]

18. Aziz, M.S.; Giribabu, N.; Rao, P.V.; Salleh, N. Pancreatoprotective effects of Geniotrigona thoracica stingless bee honey in streptozotocin-nicotinamide-induced male diabetic rats. Biomed. Pharmacother. 2017, 89, 135-145. [CrossRef]

19. Galal, R.M.; Zaki, H.F.; Seif El-Nasr, M.M.; Agha, A.M. Potential protective effect of honey against paracetamol-induced hepatotoxicity. Arch. Iran Med. 2012, 15, 674-680.

20. Erejuwa, O.O.; Sulaiman, S.A.; Ab Wahab, M.S.; Sirajudeen, K.N.; Salleh, S.; Gurtu, S. Honey supplementation in spontaneously hypertensive rats elicits antihypertensive effect via amelioration of renal oxidative stress. Oxid. Med. Cell. Longev. 2012, 2012, 374037. [CrossRef]

21. Nemoseck, T.M.; Carmody, E.G.; Furchner-Evanson, A.; Gleason, M.; Li, A.; Potter, H.; Rezende, L.M.; Lane, K.J.; Kern, M. Honey promotes lower weight gain, adiposity, and triglycerides than sucrose in rats. Nutr. Res. 2011, 31, 55-60. [CrossRef] [PubMed]

22. Hashim, K.N.; Chin, K.Y.; Ahmad, F. The Mechanism of Honey in Reversing Metabolic Syndrome. Molecules 2021, $26,808$. [CrossRef] [PubMed]

23. Terzo, S.; Mulè, F.; Caldara, G.F.; Baldassano, S.; Puleio, R.; Vitale, M.; Cassata, G.; Ferrantelli, V.; Amato, A. Pistachio Consumption Alleviates Inflammation and Improves Gut Microbiota Composition in Mice Fed a High-Fat Diet. Int. J. Mol. Sci. 2020, 21, 365. [CrossRef] [PubMed]

24. Nasuti, C.; Gabbianelli, R.; Falcioni, G.; Cantalamessa, F. Antioxidative and gastroprotective activities of anti-inflammatory formulations derived from chestnut honey in rats. Nutr. Res. 2006, 26, 130-137. [CrossRef]

25. Moroz, N.; Tong, M.; Longato, L.; Xu, H.; de la Monte, S.M. Limited alzheimer-type neurodegeneration in experimental obesity and type 2 diabetes mellitus. J. Alzheimer's Dis. 2008, 15, 29-44. [CrossRef]

26. Frisardi, V.; Solfrizzi, V.; Seripa, D.; Capurso, C.; Santamato, A.; Sancarlo, D.; Vendemiale, G.; Pilotto, A.; Panza, F. Metaboliccognitive syndrome: A cross-talk between metabolic syndrome and Alzheimer's disease. Ageing Res. Rev. 2010, 9, $399-417$. [CrossRef]

27. Pedditzi, E.; Peters, R.; Beckett, N. The risk of overweight/obesity in mid-life and late life for the development of dementia: A systematic review and meta-analysis of longitudinal studies. Age Ageing 2016, 45, 14-21. [CrossRef]

28. De la Monte, S.M. Insulin resistance and neurodegeneration: Progress towards the development of new therapeutics for Alzheimer's disease. Drugs 2017, 77, 47-65. [CrossRef]

29. Terzo, S.; Amato, A.; Mulè, F. From obesity to Alzheimer's disease through insulin resistance. J. Diabetes Its Complicat. 2021, 18, 108026. [CrossRef]

30. Mercer, J.G.; Archer, Z.A. Diet-induced obesity in the Sprague-Dawley rat: Dietary manipulations and their effect on hypothalamic neuropeptide energy balance systems. Biochem. Soc. Trans. 2005, 33, 1068-1072. [CrossRef]

31. Sa-Nguanmoo, P.; Tanajak, P.; Kerdphoo, S.; Jaiwongkam, T.; Pratchayasakul, W.; Chattipakorn, N.; Chattipakorn, S.C. SGLT2inhibitor and DPP-4 inhibitor improve brain function via attenuating mitochondrial dysfunction, insulin resistance, inflammation, and apoptosis in HFD-induced obese rats. Toxicol. Appl. Pharmacol. 2017, 333, 43-50. [CrossRef] [PubMed]

32. Pratchayasakul, W.; Sa-Nguanmoo, P.; Sivasinprasasn, S.; Pintana, H.; Tawinvisan, R.; Sripetchwandee, J.; Kumfu, S.; Chattipakorn, N.; Chattipakorn, S.C. Obesity accelerates cognitive decline by aggravating mitochondrial dysfunction, insulin resistance and synaptic dysfunction under estrogen-deprived conditions. Horm. Behav. 2015, 72, 68-77. [CrossRef] [PubMed]

33. Pintana, H.; Apaijai, N.; Pratchayasakul, W.; Chattipakorn, N.; Chattipakorn, S.C. Effects of metformin on learning and memory behaviors and brain mitochondrial functions in high fat diet induced insulin resistant rats. Life Sci. 2012, 91, 409-414. [CrossRef] [PubMed]

34. Nuzzo, D.; Baldassano, S.; Amato, A.; Picone, P.; Galizzi, G.; Caldara, G.F.; Di Carlo, M.; Mule, F. Glucagon-like peptide-2 reduces the obesity-associated inflammation in the brain. Neurobiol. Dis. 2019, 121, 296-304. [CrossRef]

35. Galizzi, G.; Palumbo, L.; Amato, A.; Conigliaro, A.; Nuzzo, D.; Terzo, S.; Caruana, L.; Picone, P.; Alessandro, R.; Mule, F.; et al. Altered insulin pathway compromises mitochondrial function and quality control both in in vitro and in vivo model systems. Mitochondrion 2021, 60, 178-188. [CrossRef]

36. Siino, V.; Amato, A.; Di Salvo, F.; Caldara, G.; Filogamo, M.; James, P.; Vasto, S. Impact of diet-induced obesity on the mouse brain phosphoproteome. J. Nutr. Biochem. 2018, 58, 102-109. [CrossRef]

37. Erejuwa, O.O.; Nwobodo, N.N.; Akpan, J.L.; Okorie, U.A.; Ezeonu, C.T.; Ezeokpo, B.C.; Nwadike, K.I.; Erhiano, E.; Wahab, M.S.A.; Sulaiman, S.A. Nigerian Honey Ameliorates Hyperglycemia and Dyslipidemia in Alloxan-Induced Diabetic Rats. Nutrients 2016, 8, 95. [CrossRef] 
38. Farakla, I.; Koui, E.; Arditi, J.; Papageorgiou, I.; Bartzeliotou, A.; Papadopoulos, G.E.; Mantzou, A.; Papathanasiou, C.; Dracopoulou, M.; Papastamataki, M.; et al. Effect of honey on glucose and insulin concentrations in obese girls. Eur. J. Clin. Invest. 2019, 49, e13042. [CrossRef]

39. De la Monte, S.M. Brain insulin resistance and deficiency as therapeutic targets in Alzheimer's disease. Curr. Alzheimer Res. 2012, 9, 35-66. [CrossRef]

40. Chepulis, L.M.; Starkey, N.J.; Waas, J.R.; Molan, P.C. The effects of long-term honey, sucrose or sugar-free diets on memory and anxiety in rats. Physiol. Behav. 2009, 97, 359-368. [CrossRef]

41. Akanmu, M.A.; Olowookere, T.A.; Atunwa, S.A.; Ibrahim, B.O.; Lamidi, O.F.; Adams, P.A.; Ajimuda, B.O.; Adeyemo, L.E. Neuropharmacological effects of Nigerian honey in mice. Afr. J. Tradit. Complementary Altern. Med. 2011, 8, 230-249. [CrossRef] [PubMed]

42. Al-Rahbi, B.; Zakaria, R.; Othman, Z.; Hassan, A.; Mohd Ismail, Z.I.; Muthuraju, S. Tualang honey supplement improves memory performance and hippocampal morphology in stressed ovariectomized rats. Acta Histochem. 2014, 116, 79-88. [CrossRef] [PubMed]

43. Rosli, N.H.M.; Yahya, H.M.; Ibrahim, F.W.; Shahar, S.; Ismail, I.S.; Azam, A.A.; Rajab, N.F. Serum Metabolomics Profiling of Commercially Mixed Functional Foods-Effects in Beta-Amyloid Induced Rats Measured Using 1H NMR Spectroscopy. Nutrients 2020, 12, 3812. [CrossRef] [PubMed]

44. Al-Himyari, F.A. The use of honey as a natural preventive therapy of cognitive decline and dementia in the Middle East. Alzheimer's Dement. 2009, 5, 24. [CrossRef]

45. Mijanur Rahman, M.; Gan, S.H.; Khalil, M.I. Neurological effects of honey: Current and future prospects. Evid. -Based Complementary Altern. Med. 2014, 2014, 958721. [CrossRef]

46. Cui, Y.; Zhang, Y.; Zhao, X.; Shao, L.; Liu, G.; Sun, C.; Xu, R.; Zhang, Z. ACSL4 exacerbates ischemic stroke by promoting ferroptosis-induced brain injury and neuroinflammation. Brain Behav. Immun. 2021, 93, 312-321. [CrossRef]

47. Nono Nankam, P.; Blüher, M. Retinol-binding protein 4 in obesity and metabolic dysfunctions. Mol. Cell. Endocrinol. 2021, 531, 111312. [CrossRef]

48. Höpfinger, A.; Berghoff, M.; Karrasch, T.; Schmid, A.; Schäffler, A. Systematic Quantification of Neurotrophic Adipokines RBP4, PEDF, and Clusterin in Human Cerebrospinal Fluid and Serum. J. Clin. Endocrinol. Metab. 2021, 106, e2239-e2250. [CrossRef]

49. Qin, H.; Yeh, W.I.; De Sarno, P.; Holdbrooks, A.T.; Liu, Y.; Muldowney, M.T. Signal transducer and activator of transcription3/suppressor of cytokine signaling-3 (STAT3/SOCS3) axis in myeloid cells regulates neuroinflammation. Proc. Natl. Acad. Sci. USA 2012, 109, 5004-5009. [CrossRef]

50. Oliva, A.A., Jr.; Kang, Y.; Sanchez-Molano, J.; Furones, C.; Atkins, C.M. STAT3 signaling after traumatic brain injury. J. Neurochem. 2012, 120, 710-720. [CrossRef]

51. Zheng, Z.V.; Chen, J.; Lyu, H.; Lam, S.Y.E.; Lu, G.; Chan, W.Y.; Wong, G.K.C. Novel role of STAT3 in microglia-dependent neuroinflammation after experimental subarachnoid haemorrhage. Stroke Vasc. Neurol. 2021, svn-2021-001028. [CrossRef] [PubMed]

52. Picone, P.; Di Carlo, M.; Nuzzo, D. Obesity and Alzheimer's disease: Molecular bases. Eur. J. Neurosci. 2020, 52, 3944-3950. [CrossRef] [PubMed]

53. Wang, C.; Zhao, F.; Shen, K.; Wang, W.; Siedlak, S.L.; Lee, H.-G.; Phelix, C.F.; Perry, G.; Shen, L.; Tang, B.; et al. The sterol regulatory element-binding protein 2 is dysregulated by tau alterations in Alzheimer disease. Brain Pathol. 2019, 29, 530-543. [CrossRef] [PubMed]

54. Lee, T.H.; Cheng, K.K.; Hoo, R.L.; Siu, P.M.; Yau, S.Y. The Novel Perspectives of Adipokines on Brain Health. Int. J. Mol. Sci. 2019, 20, 5638. [CrossRef]

55. Leuner, B.; Gould, E. Structural plasticity and hippocampal function. Annu. Rev. Psychol. 2010, 61, 111-140. [CrossRef]

56. Lin, S.; Thomas, T.C.; Storlien, L.H.; Huang, X.F. Development of high fat diet-induced obesity and leptin resistance in C57Bl/6J mice. Int. J. Obes. Relat. Metab. Disord. 2000, 24, 639-646. [CrossRef]

57. Considine, R.V.; Sinha, M.K.; Heiman, M.L.; Kriauciunas, A.; Stephens, T.W.; Nyce, M.R.; Ohannesian, J.P.; Marco, C.C.; McKee, L.J.; Bauer, T.L.; et al. Serum immunoreactive-leptin concentrations in normal-weight and obese humans. N. Engl. J. Med. 1996, 334, 292-295. [CrossRef]

58. Forny-Germano, L.; De Felice, F.G.; Vieira, M.N.D.N. The Role of Leptin and Adiponectin in Obesity-Associated Cognitive Decline and Alzheimer's Disease. Front. Neurosci. 2019, 12, 1027. [CrossRef]

59. Yang, W.-S.; Lee, W.-J.; Funahashi, T.; Tanaka, S.; Matsuzawa, Y.; Chao, C.-L.; Chen, C.-L.; Tai, T.-Y.; Chuang, L.-M. Weight reduction increases plasma levels of an adipose-derived anti-inflammatory protein, adiponectin. J. Clin. Endocrinol. Metab. 2001, 86, 3815-3819. [CrossRef]

60. Qiu, G.; Wan, R.; Hu, J.; Mattson, M.P.; Spangler, E.; Liu, S.; Yau, S.-Y.; Lee, T.M.C.; Gleichmann, M.; Ingram, D.K.; et al. Adiponectin protects rat hippocampal neurons against excitotoxicity. Age 2011, 33, 155-165. [CrossRef]

61. Guo, F.; Jiang, T.; Song, W.; Wei, H.; Wang, F.; Liu, L.; Ma, L.; Yin, H.; Wang, Q.; Xiong, L. Electroacupuncture attenuates cerebral ischemia-reperfusion injury in diabetic mice through adiponectin receptor 1-mediated phosphorylation of GSK-3 $\beta$. Mol. Neurobiol. 2015, 51, 685-695. [CrossRef] [PubMed]

62. Nair, A.B.; Jacob, S. A simple practice guide for dose conversion between animals and human. J. Basic Clin. Pharm. March 2016, 7, 27-31. [CrossRef] [PubMed] 